\title{
Short-term changes of blood pressure and aortic stiffness in older patients after transcatheter aortic valve implantation
}

This article was published in the following Dove Press journal:

Clinical Interventions in Aging

\author{
Jeannette A Goudzwaard' \\ Eleonora Disegna' \\ Marjo JAG de Ronde- \\ Tillmans ${ }^{2}$ \\ Mattie J Lenzen ${ }^{2}$ \\ Peter PT de Jaegere ${ }^{2}$ \\ Francesco US Mattace- \\ Raso' \\ 'Section of Geriatric Medicine, \\ Department of Internal Medicine, \\ Erasmus University Medical Center, \\ Rotterdam, the Netherlands; \\ ${ }^{2}$ Department of Interventional \\ Cardiology, Thoraxcenter, Erasmus \\ University Medical Center, Rotterdam, \\ the Netherlands
}

Background: Both aortic valve stenosis and aortic stiffness are moderators of arterio ventricular coupling and independent predictors of cardiovascular morbidity and mortality. Studies on the effect of transcatheter aortic valve implantation (TAVI) on aortic functional properties are limited. We performed a study to investigate the possible short-term changes in aortic stiffness and other aortic functional properties after TAVI in older patients.

Methods: TAVI Care\&Cure is an observational ongoing study including consecutive patients undergoing a TAVI procedure. Central and peripheral hemodynamic measurements were measured non invasively 1 day before (T-1) and 1 day after $(\mathrm{T}+1)$ TAVI using a validated oscillometric method using a brachial cuff (Mobil-O-Graph).

Results: 40 patients were included. Mean aortic valve area at baseline was $0.76 \pm 0.24 \mathrm{~cm}^{2}$. Indices of severity of aortic valve stenosis improved significantly. Systolic blood pressure (SBP) dropped by $8.5 \%$, from $130.3 \pm 22.9 \mathrm{mmHg}$ to $119.5 \pm 15.8 \mathrm{mmHg}(p=0.005)$. Diastolic blood pressure (DBP) dropped by $13.1 \%$ from $74.8 \pm 14.5 \mathrm{mmHg}$ to $65.0 \pm 11.3 \mathrm{mmHg}$ $(p<0.001)$. The arterial pulse wave velocity (aPWV) decreased from $12.05 \pm 1.99 \mathrm{~m} / \mathrm{s}$ to $11.6 \pm 1.56 \mathrm{~m} / \mathrm{s}(p=0.006)$. Patients with high aPWV at baseline showed a significantly larger reduction in SBP in comparison to patients with low aPWV: $-20.3 \mathrm{mmHg}(-14.1 \%) \mathrm{vs}-3.1$ mmHg $(-2.6 \%)$, respectively $(p=0.033)$. The same trend was found for the DBP: -16.2 $(-20.4 \%)$ vs $-4.5 \mathrm{mmHg}(-6.3 \%)$ for high vs low aPWV at baseline $(p=0.037)$.

Conclusion: We found short-term changes in blood pressure and aortic stiffness after TAVI. The amplitude of the changes was the largest in patients with elevated aortic stiffness at baseline.

Keywords: aortic valve stenosis, aortic stiffness, blood pressure levels, TAVI

\section{Introduction}

Aortic valve stenosis (AoS) is a common degenerative disease in older persons and associated with poor prognosis. ${ }^{1,2}$ AoS should not only be considered a valvular disease, but also an atherosclerotic like process leading to compromised systemic arterial compliance. ${ }^{3-5}$ Arterial stiffness has emerged as an independent predictor of cardiovascular risk and mortality. ${ }^{2,6}$

AoS and reduced systemic arterial compliance jointly contribute to the increase of the left ventricular afterload affecting the left ventricular function and ventricular remodeling ${ }^{7}$. Both are moderators of the arterio ventricular coupling, which can be considered as a determinant of cardiovascular system performance. ${ }^{8}$ Therefore, structural changes of one component (ie, restore normal flow patterns of the aortic
Correspondence: Jeannette A Goudzwaard

Section of Geriatric Medicine, Department of Internal Medicine, Erasmus University Medical Center, Dr. Molenwaterplein 40, Rotterdam 30I5 GD, The Netherlands

Tel +3 I I 0735979

Email j.goudzwaard@erasmusmc.nl 
valve by replacing the degenerated valve) could have an effect on other components, such as aortic stiffness.

Previous studies have investigated changes in systolic blood pressure (SBP) and diastolic blood pressure (DBP) as well as aortic stiffness after surgical aortic valve replacement (SAVR), ${ }^{9-12}$ and one study observed improvement of aortic distensibility. ${ }^{11}$ At present, there is little and conflicting information on the short-term aortic functional properties after transcatheter aortic valve implantation (TAVI). ${ }^{12-14}$ The objective of this study was to assess the effect of TAVI on aortic stiffness and blood pressure levels shortly after TAVI.

\section{Methods}

\section{Study population}

The study population consists of 40 consecutive patients with severe symptomatic AoS undergoing TAVI between May and August 2017. All patients were accepted for TAVI following the multidisciplinary Heart Team that included interventional cardiologists, cardiac surgeons, anesthetists and geriatricians. ${ }^{15}$

The medical Ethics Committee of the Erasmus Medical center reviewed the study (MEC-2014-277), and since this study was not subjected to the Dutch Medical Research Involving Human Subjects Act no approval was required. However, the study was conducted according to the Helsinki Declaration and all patients gave written informed consent to participate in this study after being informed of its nature and purpose. There were no specific exclusion criteria.

Prior to TAVI, patients were seen in the cardiology outpatient clinic. Baseline cardiology assessment included a full medical history including inventory of cardiovascular risk factors and determining symptoms using the New York Heart Association (NYHA) classification and the Canadian Cardiovascular Society (CCS) grading of angina pectoris, physical examination and electrocardiogram (ECG). Further cardiologic examination included echocardiography, coronary angiography and multislice computed tomography (MSCT) to address the aortic valve and arterial tree and determine technical suitability for TAVI and access site. ${ }^{16,17}$

\section{Hemodynamics}

Hemodynamic measurements consisted of the measurements of SBP and DBP $(\mathrm{mmHg})$, mean arterial pressure $(\mathrm{mmHg})$, pulse pressure $(\mathrm{mmHg})$, heart rate $(\mathrm{bpm})$, stroke volume
$(\mathrm{mL})$, cardiac output $(1 / \mathrm{min})$, cardiac index $\left(1 / \mathrm{m}^{*} 1 / \mathrm{m}\right)$, augmentation index (\%), peripheral vascular resistance $\left(\mathrm{s}^{*} \mathrm{mmHg} / \mathrm{mL}\right)$ and aortic pulse wave velocity (aPWV) $(\mathrm{m} / \mathrm{s}) .{ }^{2}$ aPWV is the gold standard assessment tool for arterial stiffness, providing information about functional elastic property and structural unity of the vessel wall. ${ }^{18-22}$ Measurements were performed the day before (T-1) and the day after $(\mathrm{T}+1)$ using the non invasive Mobil-O-Graph (Mobil-O-Graph 24h PWA Monitor, I.E.M. GmbH, Stolberg, Germany). This electronic blood pressure oscillometric monitoring system uses a simple upper arm cuff and has specific validated software to calculate the aPWV and the other hemodynamic parameters described above. ${ }^{23}$ Hemodynamic measurements on $\mathrm{T}-1$ and $\mathrm{T}+1$ were taken in the morning after 10 mins resting in the supine position.

\section{Echocardiography}

All patients underwent a two-dimensional echocardiography and Doppler study before the procedure and before hospital discharge according to standard methods. ${ }^{24}$ Ejections fraction (\%), peak velocity of the aortic valve $(\mathrm{m} / \mathrm{S})$ and both the peak and mean transvalvular gradient of the aortic valve $(\mathrm{mmHg})$ were assessed using transthoracic echocardiography.

\section{TAVI procedure}

TAVI was performed either under general or local anesthesia following the decision of the multi disciplinary heart team. General anesthesia was used in 2 patients and the other 38 patients received local anesthesia. The transfemoral arterial approach was used for 39 patients and 1 patient was surgically accessed through the axillary artery. Patients were admitted to the intensive coronary care unit for monitoring up to a minimum of 4 hrs. Perioperative, there were no procedural standard medication alterations.

\section{Statistical analysis}

Categorical variables are presented as numbers and corresponding percentages. Continuous variables are expressed as means $\pm \mathrm{SD}$ or median values with corresponding IQRs. Differences between groups (one group examining variables before and after TAVI, the other group comparing patients with low and high aPWV at baseline) were compared with the paired $t$-test and the independent $t$-test or its non parametric equivalents, respectively. Spearman's correlation coefficients were used to test the correlation between variables. 
Furthermore, we performed analyses stratified for categories of aortic stiffness. Participants were divided as having low or high aortic stiffness based on the baseline median aPWV value $(11.9 \mathrm{~m} / \mathrm{s})$. We performed univariate analysis within the two groups of low and high aPWV as fixed factor and the hemodynamic value of interest as the dependent value. Models were adjusted for age, and the variable of interest at T-1 (ie, SBP at T-1 was included in models investigating the change of SBP levels). Data were analyzed with statistic program IBM Statistical Package for Social Science for Windows version 21 (SPSS). $p$-value of $\leq 0.05$ was considered statistically significant.

\section{Results}

\section{Baseline characteristics}

The baseline characteristics are summarized in Table 1 . Mean age was $80.1 \pm 7.6$ years, $42.5 \%$ were women. The prevalence of hypertension was $61.5 \%$. Mean SBP was $130.3 \pm 22.9 \mathrm{mmHg}$ and the mean pulse wave velocity was

Table I Demographic and clinical data $(n=40)$

\begin{tabular}{|l|l|}
\hline Age (years \pm SD) & $80.1 \pm 7.6$ \\
\hline Women (\%) & 42.5 \\
\hline BMI (kg/m ${ }^{2}$ ) & $26.8 \pm 3.6$ \\
\hline Cardiovascular risk factors & \\
Hypertension (\%) & 61.5 \\
Dyslipidemia (\%) & 59.0 \\
Diabetes mellitus (\%) & 27.5 \\
Current smoker (\%) & 5.1 \\
Family history of CAD (\%) & 30.8 \\
\hline Medication & \\
B-blockers (\%) & 20.0 \\
ACE/ARB (\%) & 27.5 \\
Calcium antagonists (\%) & 22.5 \\
Nitrates (\%) & 7.5 \\
Diuretics (\%) & 55.0 \\
\hline Comorbidities & \\
Coronary artery disease (\%) & 35.0 \\
Previous stroke (\%) & 30.8 \\
COPD (\%) & 26.6 \\
Renal disease (\%) & 30.8 \\
\hline Symptoms & \\
NYHA Class 3 or 4 (\%) & 50.0 \\
Angina CCS classification 3 or 4 (\%) & 0.0 \\
Vertigo (\%) & 36.8 \\
\hline
\end{tabular}

Abbreviations: $\mathrm{BMI}$, body mass index; $\mathrm{ACE}$, angiotensin-converting enzyme inhibitor; ARB, angiotensin II receptor blockers; NYHA, New York Heart Association; CCS, Canadian Cardiovascular Society; CAD, coronary artery disease; COPD, Chronic Obstructive Pulmonary Disease.
$12.1 \pm 1.9 \mathrm{~m} / \mathrm{s}$. The mean aortic valve area was 0.76 $\pm 0.24 \mathrm{~cm}$.

\section{Echocardiographic and hemodynamic changes after TAVI}

Table 2 shows the echocardiographic and hemodynamic changes on $\mathrm{T}-1$ and $\mathrm{T}+1$. The aPWV and augmentation index and peripheral vascular resistance decreased significantly ( $p=0.006, p<0.002$ and $p<0.001)$.

The aPWV measured before TAVI (T-1) correlated with the change in SBP (Spearman's rho $=-0.603$, $p<0.001$ ), DBP (Spearman's rho $=-0.477, p=0.002$ ), peripheral vascular resistance (Spearman's rho $=-0.338$, $p=0.033$ ) and aPWV (Spearman's rho $=-0.583, p<0.001$ ). The aPWV measured before TAVI (T-1) did not correlate with the change in augmentation index (Spearman's rho = $-0.282, p=0.078$ ) (Figure 1). Patients were subsequently divided into two groups (low and high aortic stiffness) according to the median value of aPWV at baseline. Patients with high aPWV at baseline showed a significantly larger reduction in SBP in comparison to patients with low aPWV: $-20.3 \mathrm{mmHg}(-14.1 \%)$ vs $-3.1 \mathrm{mmHg}$ $(-2.6 \%)$, respectively $(p=0.033)$. A similar trend was found when analyzing the changes of the DBP: -16.2 $\mathrm{mmHg}(-20.4 \%)$ vs $-4.5 \mathrm{mmHg}(-6.3 \%)$ for high vs low aPWV at baseline $(p=0.037)$. Cardiac output increased in the high aPWV group with $4.6 \mathrm{~mL} / \mathrm{min}(+4.5 \%)$ and $0.78 \mathrm{~mL} / \mathrm{min}(+16 \%)$ in the low aPWV baseline group, although not significant $(p=0.33)$. The change in augmentation index, peripheral resistance and aPWV differed between the two groups with low and high aPWV measured before TAVI (T-1), but not significantly ( $p=0.993$; $p=0.430 ; p=0.169$ resp.) (Figure 2).

\section{Discussion}

In this study, we found short-term decrease in blood pressure levels and aortic stiffness after TAVI in older patients. The amplitude of the changes was largest in patients with elevated aortic stiffness at baseline.

The impact of aortic valve replacement on hemodynamic parameters such as aortic stiffness has been previously investigated in relatively small groups of patients receiving both SAVR and TAVI and results are controversial. In a study investigating only SAVR patients, the aortic distensibility showed progressive improvement up to 1 year after the intervention. This study also showed that blood pressure significantly dropped up to 3 weeks after SAVR. ${ }^{11}$ Another study compared the effects of both SAVR and 
Table 2 Echocardiographic and hemodynamic changes at baseline and after TAVI

\begin{tabular}{|c|c|c|c|}
\hline Variable & T-I & $\mathbf{T + 1}$ & $P$-value \\
\hline \multicolumn{4}{|l|}{ Echocardiographic measurements } \\
\hline Ejection fraction (\%) & $55.4 \pm 12.7$ & $55.6 \pm 11.9$ & 0.576 \\
\hline Peak AoV $(\mathrm{m} / \mathrm{s})$ & $4.1 \pm 0.7$ & $2.1 \pm 0.4$ & $<0.0001$ \\
\hline Peak transvalvular gradient $(\mathrm{mmHg})$ & $68.2 \pm 23.2$ & $17.0 \pm 7.9$ & $<0.001$ \\
\hline Mean transvalvular gradient $(\mathrm{mmHg})$ & $41.5 \pm 15.7$ & $9.5 \pm 5.3$ & $<0.001$ \\
\hline \multicolumn{4}{|l|}{ Hemodynamic measurements } \\
\hline Systolic blood pressure $(\mathrm{mmHg})$ & $130.3 \pm 22.9$ & $119.5 \pm 15.8$ & 0.005 \\
\hline Diastolic blood pressure $(\mathrm{mmHg})$ & $74.8 \pm 14.5$ & $65.0 \pm 11.3$ & $<0.001$ \\
\hline Mean arterial pressure $(\mathrm{mmHg})$ & $100.1 \pm 17.0$ & $89.9 \pm 12.1$ & 0.001 \\
\hline Pulse pressure $(\mathrm{mmHg})$ & $55.6 \pm 16.1$ & $54.5 \pm 12.5$ & 0.64 \\
\hline Heart rate (bpm) & $66.6 \pm 13.0$ & $70.3 \pm 10.2$ & 0.081 \\
\hline Stroke volume $(\mathrm{mL})$ & $71.9 \pm 12.5$ & $75.8 \pm 18.1$ & 0.25 \\
\hline Cardiac output (L/min) & $4.7 \pm 0.9$ & $5.3 \pm 1.1$ & 0.019 \\
\hline Cardiac index $\left(\mathrm{L} / \mathrm{m}^{*} \mathrm{I} / \mathrm{m}^{2}\right)$ & $2.5 \pm 0.6$ & $2.8 \pm 0.6$ & 0.023 \\
\hline Augmentation index (\%) & $27.7 \pm 13.9$ & $17.6 \pm 13.6$ & 0.002 \\
\hline Aortic pulse wave velocity $(\mathrm{m} / \mathrm{s})$ & $12.1 \pm 1.9$ & $11.6 \pm 1.6$ & 0.006 \\
\hline Peripheral vascular resistance $\left(\mathrm{s}^{*} \mathrm{mmH} / \mathrm{mL}\right)$ & $|.3| \pm 0.3$ & $1.07 \pm 0.2$ & $<0.001$ \\
\hline
\end{tabular}

Notes: T-I: I day before TAVI. T+I: I day after TAVI.

Abbreviation: AoV, aortic valve.

TAVI on aortic stiffness and found that treatment of severe AoS by SAVR, but not with TAVI, was associated with an increase in aortic stiffness at 6 months. ${ }^{25}$ Conversely, other authors found no significant change in aortic stiffness after replacing the aortic valve in both SAVR and TAVI patients. $^{12}$

In a population of 23 patients treated with TAVI, a significant decrease of aortic compliance and arterial elastance was found. ${ }^{13}$ On the contrary, in a slightly larger population of 30 patients, there was no change found in the elasticity of the aorta after TAVI. ${ }^{14}$

In our study, we found a short-term decrease in blood pressure levels and aortic stiffness after TAVI. The short-term decrease in hemodynamic measurements after TAVI and the large amplitude in patients with high aPWV might be a consequence of the changes in the arterio ventricular coupling due to the replacement of the degenerated aortic valve.

We also found that for the total study population cardiac output and cardiac index increased significantly after TAVI with an also significant decrease in augmentation index and peripheral vascular resistance. When we divided patients into two groups of low and high aPWV before TAVI, we could not find a significant difference between the two groups of low and high aPWV at baseline. It could be speculated that the effect of the changed arterioventricular coupling has a similar effect on these hemodynamic variables, whether or not patients have low or high aPWV values before TAVI.

Since AoS is no longer considered as an isolated aortic valve disease but rather a complex disease in which the central actors are the left ventricle (ability to adapt to the increased afterload), the valve (severity of valvular obstruction) and the vascular system (reduced arterial compliance), ${ }^{26}$ a change in one of the components could well lead to a change in one of the other determinants.

AoS leads to increased left ventricular afterload, effecting left ventricular function and ventricular remodeling, ${ }^{7}$ which are determinants of impaired aortic stiffness. ${ }^{18}$

The correlation of aortic stiffness and severity of AoS has been investigated, ${ }^{12,27,28}$ and although controversial, the hypothesis that if aortic stiffness and severity of AoS are correlated by interacting in the arterio ventricular coupling, one could assume that restoring hemodynamic parameters of the aortic valve, the aortic stiffness will decrease. Another hypothesis is that the turbulent flow across the stenotic aortic valve may damage aortic root endothelium, leading to alterations of the elastic properties of the aorta and that by replacing the degenerated valve, which leads to recovery of the aortic root endothelium, vascular elasticity can improve. ${ }^{11,29}$ Since we measured aortic stiffness very shortly after TAVI, this theory will presumably not be applicable in the present study, since 


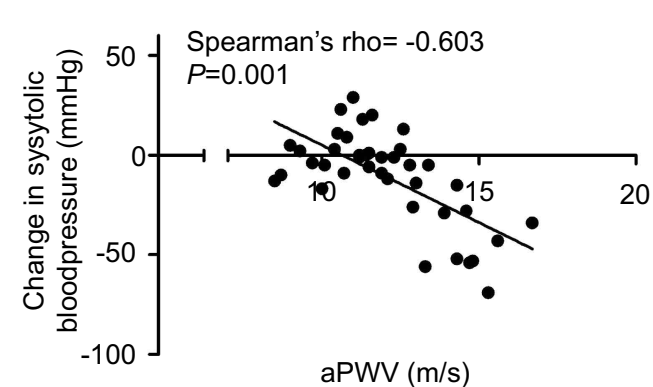

A
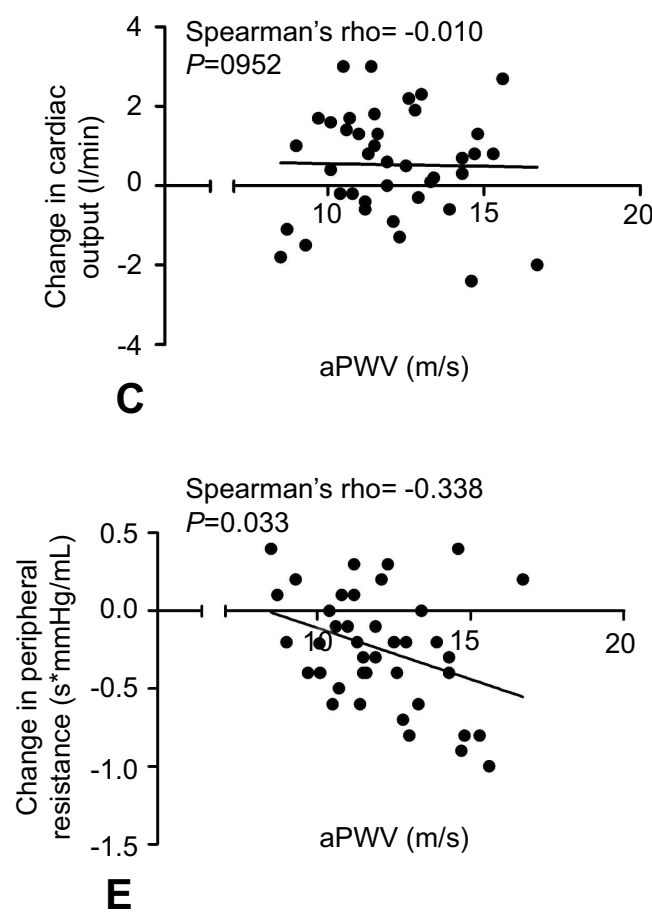

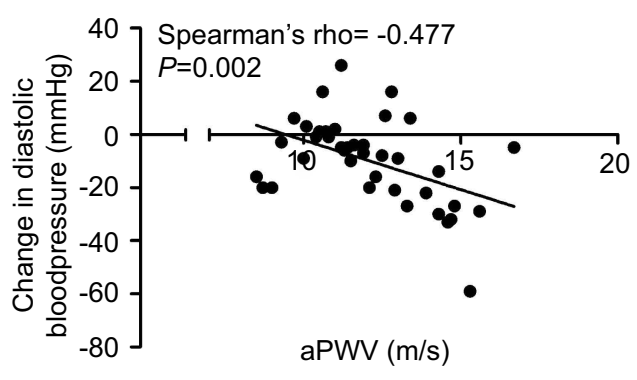

B
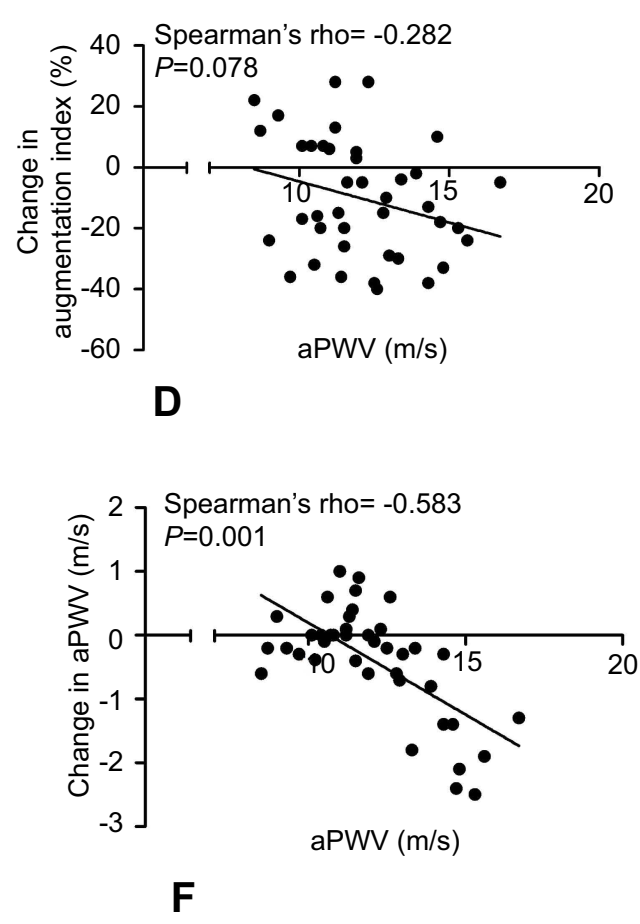

Figure I Changes in hemodynamic measurements correlated to baseline aPWV. Change in systolic blood pressure (A), diastolic blood pressure (B), cardiac output (C), augmentation index $(\mathbf{D})$, peripheral resistance $(\mathbf{E})$, aPWV $(\mathbf{F})$ according to aPWV at baseline.

Abbreviation: aPWV, aortic pulse wave velocity.

the time span seems to be too short to already see the effect of changed endothelium function on aortic stiffness.

Further research could be focusing on the role of the impact of changes in aortic stiffness and hemodynamic parameters on mortality and other clinical outcomes. In an aged and multimorbid population, specific prognostic tools would be helpful in further clinical decision-making on whether or not to treat patients. The valvulo arterial impedance, for example, a parameter that incorporates both arterial impedance and valve severity, ${ }^{7,30}$ 3has shown to have predictive value for outcome in medically managed aortic stenosis patients, but also has been shown to be associated with increased longterm mortality. ${ }^{1}$
The present study has some limitations. First, we included a relatively small number of patients; therefore, the results need to be replicated in a larger group of patients. Second, there were no standard medication changes in antihypertensive drug regiments; however, changes in drug treatment during the procedure were not registered. Since the measurements of the hemodynamic parameters were only 1 day after TAVI, the risk of measuring the effect of changes in antihypertensive drug regiments is probably limited.

Third, in this study we have not included inflammatory markers in our analysis. Previous studies have described significant correlations between inflammatory markers and 

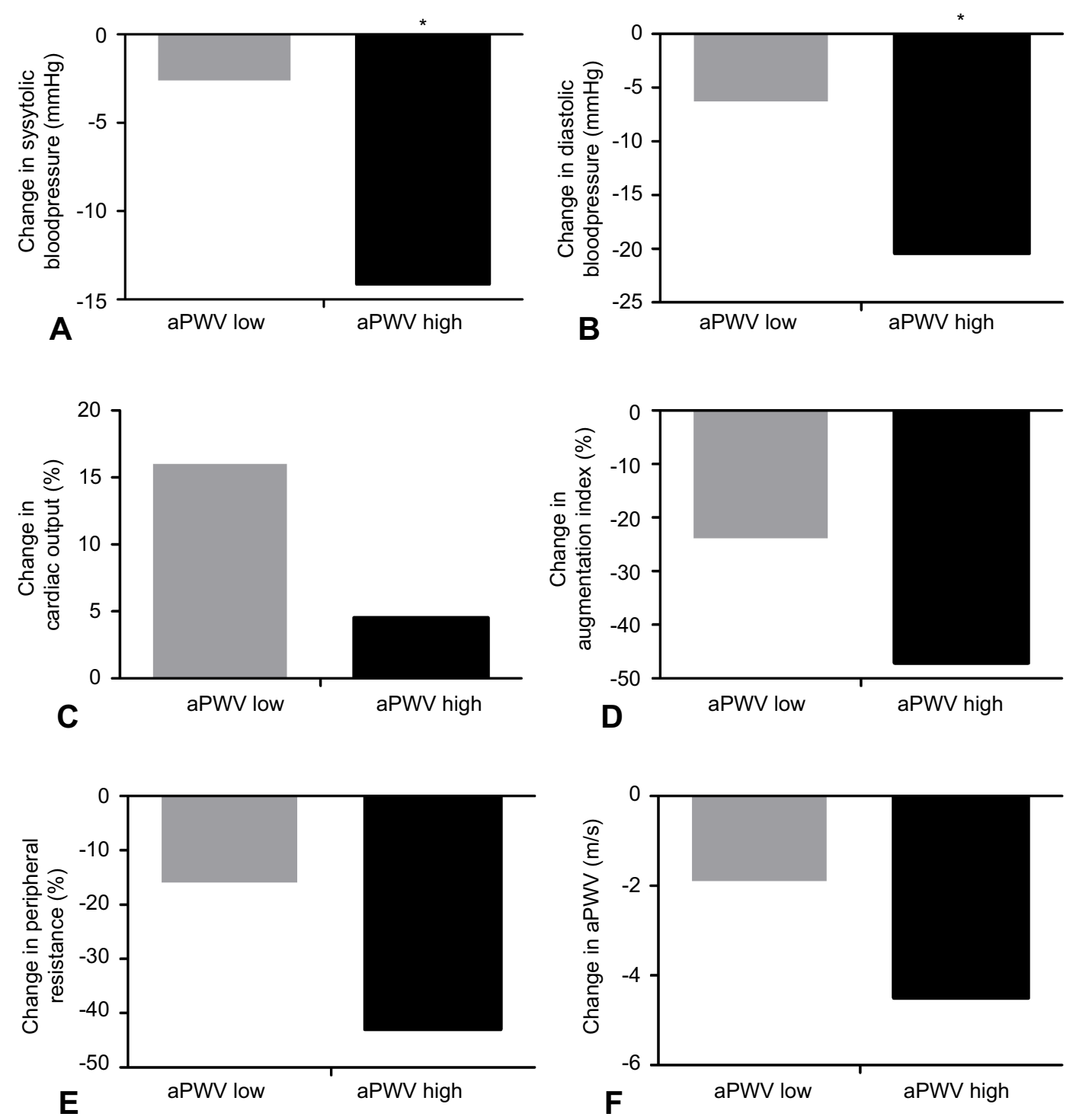

Figure 2 Percentual changes in hemodynamic measurements. Percentual change in systolic blood pressure (A), diastolic blood pressure (B), cardiac output (C), augmentation index $(\mathbf{D})$, peripheral resistance $(\mathbf{E})$, aPWV $(\mathbf{F})$ when patients are divided according to high and low aPWV at baseline.

Notes: $(\mathbf{A})$ SBP: aPWV low vs aPWV high $(p=0.033)$. (B) DBP: aPWV low vs aPWV high $(p=0.037)$. * $p<0.05$.

Abbreviations: SBP, systolic blood pressure; DBP, diastolic blood pressure; CO, cardiac output; aPWV, aortic pulse wave velocity.

severity of arterial stiffness, in a wide variety of patient populations including those with the same comorbidities as our study population. ${ }^{32}$

In conclusion, we found a short-term decrease in blood pressure levels and aortic stiffness after TAVI. The amplitude of these changes was larger in patients with elevated aortic stiffness at baseline.

\section{Highlights}

- Aortic valve stenosis and aortic stiffness are both moderators of atrioventricular coupling.
- We observed a decrease in blood pressure levels and aortic stiffness in the short-term period after TAVI.

- The amplitude of these changes was larger in patients with elevated aortic stiffness at baseline.

\section{Acknowledgments}

The present work has been presented in part as abstract on the ARTERY Conference, October 18-20, 2018, Guimaraes, Portugal. This research did not receive any specific grant from funding agencies in the public, commercial or not-for-profit sectors. 


\section{Disclosure}

The authors report no conflicts of interest in this work.

\section{References}

1. Iung B, Baron G, Butchart EG, et al. A prospective survey of patients with valvular heart disease in Europe: the Euro heart survey on valvular heart disease. Eur Heart J. 2003;24(13):1231-1243. doi:10.1016/s0195-668x(03)00201-x

2. Mattace-Raso FU, van der Cammen TJ, Hofman A, et al. Arterial stiffness and risk of coronary heart disease and stroke: the Rotterdam study. Circulation. 2006;113(5):657-663. doi:10.1161/CIRCULATI ONAHA.105.555235

3. Poggianti E, Venneri L, Chubuchny V, Jambrik Z, Baroncini LA, Picano E. Aortic valve sclerosis is associatedwith systemic endothelial dysfunction. $J$ Am Coll Cardiol. 2003;41(1):136-141.

4. Pibarot P, Dumesnil JG. Assessment of Aortic Stenosis Severity: Check the Valve but Don't Forget the Arteries! Heart.2007;93 (7):780-2. doi: $10.1136 /$ hrt.2006.111914.

5. Freeman RV, Otto CM. Spectrum of calcific aortic valve disease. Circulation. 2005;111(24):3316-3326. doi:10.1161/CIRCULATION AHA. 104.486738

6. Vlachopoulos C, Aznaouridis K, Stefanadis C. Prediction of cardiovascular events and all-cause mortality with arterial stiffness: a systematic review and meta-analysis. J Am Coll Cardiol. 2010;55 (13):1318-1327. doi:10.1016/j.jacc.2009.10.061

7. Briand M, Dumesnil JG, Kadem L, et al. Reduced systemic arterial compliance impacts significantly on left ventricular afterload and function in aortic stenosis: implications for diagnosis and treatment. J Am Coll Cardiol. 2005;46(2):291-298. doi:10.1016/j. jacc.2004.10.081

8. Chirinos JA. Ventricular-arterial coupling: invasive and noninvasive assessment. Artery Res. 2013;7(1):2-14. doi:10.1016/j. artres.2012.12.002

9. Gotzmann M, Lindstaedt M, Bojara W, Mügge A, Germing A. Hemodynamic results and changes in myocardial function after transcatheter aortic valve implantation. Am Heart J. 2010;159(5):926-932. doi:10.1016/j.ahj.2010.02.030

10. Vizzardi E, D'Aloia A, Fiorina C, et al. Early regression of left ventricular mass associated with diastolic improvement after transcatheter aortic valve implantation. $J$ Am Soc Echocardiography. 2012;25(10):1091-1098. doi:10.1016/j.echo.2012.06.010

11. Nemes A, Galema TW, Soliman OI, Bogers AJ, Folkert J, Geleijnse ML. Improved aortic distensibility after aortic homograft root replacement at long-term follow-up. Int J Cardiol. 2009;136(2):216-219. doi:10.1016/j.ijcard.2008.04.049

12. Bruschi G, Maloberti A, Sormani P, et al. Arterial stiffness in aortic stenosis: relationship with severity and echocardiographic procedures response. High Blood Pressure Cardiovasc Prev. 2017;24(1):19-27. doi:10.1007/s40292-016-0176-x

13. Yotti R, Bermejo J, Gutiérrez-Ibañes E, et al. Systemic vascular load in calcific degenerative aortic valve stenosis: insight from percutaneous valve replacement. $J$ Am Coll Cardiol. 2015;65(5):423-433. doi:10.1016/j.jacc.2014.10.067

14. Vavuranakis M, Vrachatis DA, Boudoulas H, et al. Effect of transcatheter aortic valve implantation on the ascending aorta's elasticity. Clin Res Cardiol. 2012;101(11):895-899. doi:10.1007/s00392-0120473-x

15. de Ronde-Tillmans MJ, Lenzen MJ, Abawi M, Van Mieghem NM, Zijlstra F, De Jaegere PP. 10 years of transcatheter aortic valve implantation: an overview of the clinical applicability and findings. Ned Tijdschr Geneeskd. 2013;158:A7768-A.
16. de Jaegere P, Kappetein AP, Knook M, et al. Percutaneous aortic valve replacement in a patient who could not undergo surgical treatment. A case report with the CoreValve aortic valve prosthesis. EuroIntervention. 2006;1(4):475.

17. Schultz CJ, Moelker AD, Tzikas A, et al. Cardiac CT: necessary for precise sizing for transcatheter aortic implantation. EuroIntervention. 2010;6:G6-G13.

18. Cantürk E, Çakal B, Karaca O, et al. Changes in aortic pulse wave velocity and the predictors of improvement in arterial stiffness following aortic valve replacement. Ann Thoracic Cardiovasc Surg. 2017;23(5):248-255. doi:10.5761/atcs.oa.17-00062

19. Benetos A, Adamopoulos C, Bureau J-M, et al. Determinants of accelerated progression of arterial stiffness in normotensive subjects and in treated hypertensive subjects over a 6-year period. Circulation. 2002;105(10):1202-1207. doi:10.1161/hc1002.105135

20. Laurent S, Cockcroft J, Van Bortel L, et al. Expert consensus document on arterial stiffness: methodological issues and clinical applications. Eur Heart J. 2006;27(21):2588-2605. doi:10.1093/eurheartj/ehl254

21. Reference Values for Arterial Stiffness C. Determinants of pulse wave velocity in healthy people and in the presence of cardiovascular risk factors: 'establishing normal and reference values'. Eur Heart J. 2010;31(19):2338-2350. doi:10.1093/eurheartj/ehq165

22. Van Bortel LM, Laurent S, Boutouyrie P, et al. Expert consensus document on the measurement of aortic stiffness in daily practice using carotid-femoral pulse wave velocity. J Hypertens. 2012;30 (3):445-448. doi:10.1097/HJH.0b013e32834fa8b0

23. Hametner B, Wassertheurer S, Kropf J, Mayer C, Eber B, Weber T. Oscillometric estimation of aortic pulse wave velocity: comparison with intra-aortic catheter measurements. Blood Press Monit. 2013;18 (3):173-176. PubMed PMID: ISI:000319694600009. English. doi:10.1097/MBP.0b013e3283614168

24. Otto C, Pearlman A. Valvular Stenosis: Diagnosis, Quantitation, and Clinical Approach. Textbook of Clinical Echocardiography. Philadelphia, PA: WB Saunders Co; 1995:209-242.

25. Musa TA, Uddin A, Fairbairn TA, et al. Assessment of aortic stiffness by cardiovascular magnetic resonance following the treatment of severe aortic stenosis by TAVI and surgical AVR. J Cardiovasc Magn Reson. 2016;18(1):37. doi:10.1186/s12968-016-0256-z

26. Weisz SH, Magne J, Dulgheru R, Caso P, Piérard LA, Lancellotti P. Carotid artery and aortic stiffness evaluation in aortic stenosis. $J$ Am Soc Echocardiography. 2014;27(4):385-392. doi:10.1016/j. echo.2013.12.014

27. Ping-Yen L, Wei-Chuan T, Chih-Chan L, Chih-Hsin H, Haung -Y-Y, Jyh-Hong C. Invasive measurements of pulse wave velocity correlate with the degree of aortic valve calcification and severity associated with matrix metalloproteinases in elderly patients with aortic valve stenosis. Clin Sci. 2004;107(4):415-422. doi:10.1042/CS20040098

28. Çelik Ş, Durmuş İ, Korkmaz L, et al. Aortic pulse wave velocity in subjects with aortic valve sclerosis. Echocardiography. 2008;25 (10):1112-1116. doi:10.1111/j.1540-8175.2008.00728.x

29. Et-Taouil K, Safar M, Plante GE. Mechanisms and consequences of large artery rigidity. Can J Physiol Pharmacol. 2003;81(3):205-211. doi: $10.1139 / \mathrm{y} 03-022$

30. Hachicha Z, Dumesnil JG, Pibarot P. Usefulness of the valvuloarterial impedance to predict adverse outcome in asymptomatic aortic stenosis. J Am Coll Cardiol. 2009;54(11):1003-1011. doi:10.1016/j. jacc.2009.04.079

31. Kobayashi Y, Kim JB, Moneghetti KJ, et al. Dynamic changes in aortic impedance after transcatheter aortic valve replacement and its impact on exploratory outcome. Int J Cardiovasc Imaging. 2017;33 (11):1693-1701. doi:10.1007/s10554-017-1155-6

32. Mozos I, Malainer C, Horbańczuk J, et al. Inflammatory markers for arterial stiffness in cardiovascular diseases. Front Immunol. 2017;8:1058. doi:10.3389/fimmu.2017.01058 


\section{Publish your work in this journal}

Clinical Interventions in Aging is an international, peer-reviewed journal focusing on evidence-based reports on the value or lack thereof of treatments intended to prevent or delay the onset of maladaptive correlates of aging in human beings. This journal is indexed on PubMed Central, MedLine, CAS, Scopus and the Elsevier
Bibliographic databases. The manuscript management system is completely online and includes a very quick and fair peer-review system, which is all easy to use. Visit http://www.dovepress.com/ testimonials.php to read real quotes from published authors. 